\title{
Somatosensory Evoked Potentials as a Useful Tool to Limit the Temporary Clipping Time during Aneurysm Clipping
}

\author{
Deepak Rajappa ${ }^{1}$ \\ ${ }^{1}$ Division of Neuroanaesthesia, Department of Anaesthesia, Sakra \\ World Hospital, Bengaluru, Karnataka, India \\ 2Department of Neurosurgery, Sakra World Hospital, Bengaluru, \\ Karnataka, India
}

J Neuroanaesthesiol Crit Care 2021;8:223-224.

Perioperative neurological deficit is one of the known complications of cerebral aneurysm clipping procedures, leading to significant morbidity and mortality of the patients. ${ }^{1}$ Neurological deficits noticed immediately in the postoperative period are often due to prolonged temporary or permanent clipping on adjacent vessels. Intraoperative somatosensory evoked potentials (SSEPs) have been in use to predict postoperative neurological deficits. ${ }^{2}$

Here is a 56-year-old male patient presenting with sudden onset of left upper limb weakness lasting for 15 minutes and complete recovery later. After further investigating with computed tomography angiography, a giant saccular aneurysm was detected in the right middle cerebral artery (MCA) of $25.5^{*} 9.92 \mathrm{~mm}$ in size. The patient was planned for right pterional craniotomy and clipping of the aneurysm along with SSEP monitoring. During dissection, the aneurysm appeared
Address for correspondence Deepak Rajappa, MD, DM, Division of Neuroanaesthesia, Department of Anaesthesia, Sakra World Hospital, SY NO 52/2 \& 52/3, Devarabeesanahalli, Varthur Hobli Opposite Intel, Outer Ring Road, Marathahalli, Bengaluru, Karnataka 560103, India (e-mail: drdeepak.r4@gmail.com).

thrombosed; expurgation of the thrombosis was done with temporary clip placed in right internal carotid artery and MCA distal to the aneurysm. SSEPs were continuously monitored during the course. Median and posterior tibial nerve SSEPs were recorded from the scalp electrodes placed at C3 and C4. The current was applied at a voltage of 15 to 25 milliamperes, frequency of $3 \mathrm{~Hz}$, and pulse duration of 300 microseconds with an average of 300 times. Alarm criteria used in this case were reduction in $50 \%$ of the amplitude or increase in the latency by $10 \%$ from baseline. After 11 minutes of temporary clipping time, a drop in the amplitude of SSEP more than 50\% was observed ( - Fig. 1). In another 3 minutes, complete loss of the evoked potentials was observed both in the lower limbs and upper limbs, with a steady-state anesthesia and vitals maintained around the baseline. SSEPs returned to normal immediately after removal of the temporary clips in place.

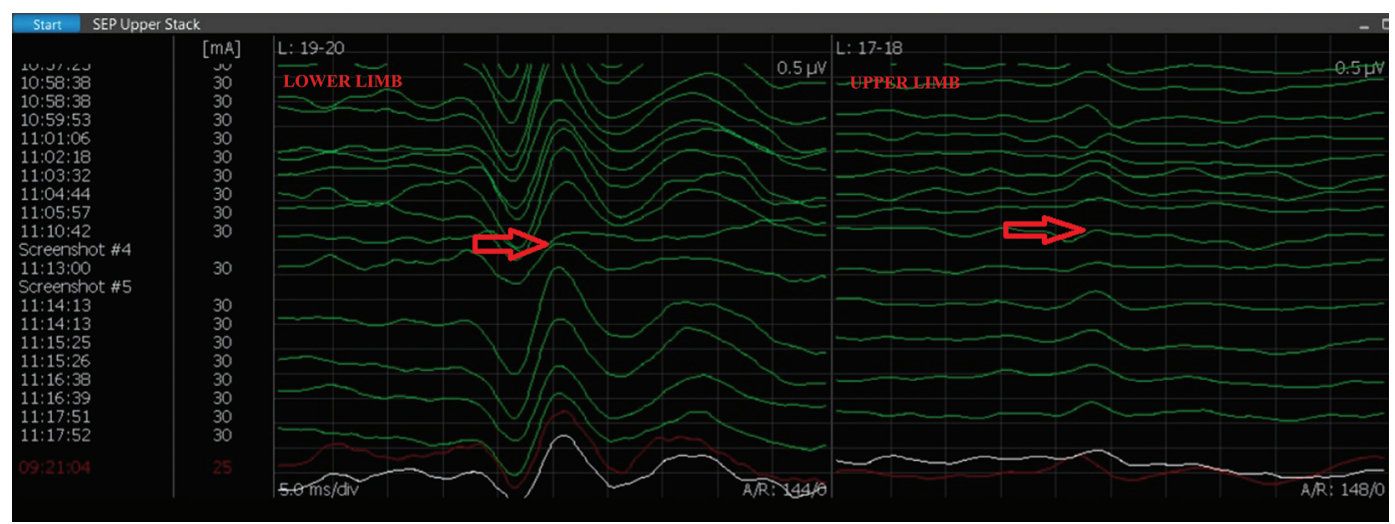

Fig. 1 Drop in amplitude of somatosensory evoked potential of both lower limb and upper limb indicated by arrows during temporary clipping and recovery after removal of the clipping.

published online

November 19, 2020
DOI https://doi.org/

$10.1055 / \mathrm{s}-0040-1716946$

ISSN 2348-0548.
(C) 2020. Indian Society of Neuroanaesthesiology and Critical Care.

This is an open access article published by Thieme under the terms of the Creative Commons Attribution-NonDerivative-NonCommercial-License, permitting copying and reproduction so long as the original work is given appropriate credit. Contents may not be used for commercial purposes, or adapted, remixed, transformed or built upon. (https://creativecommons.org/licenses/by-nc-nd/4.0/)

Thieme Medical and Scientific Publishers Pvt. Ltd., A-12, 2nd Floor, Sector 2, Noida-201301 UP, India 
Temporary clips were reapplied after waiting for 10 minutes. Permanent clips were placed at the neck of the aneurysm and excision of the aneurysm wall was done in 7 minutes. No change in SSEP was observed at this time. Further intraoperative course was uneventful and the patient was extubated. The power in the left upper limb decreased to 4/5 in the postoperative period that recovered to baseline in 12 hours.

The reduced blood flow during temporary clipping can cause reversible neurological changes. However, if not dealt immediately, there can be irreversible damage. ${ }^{3}$ SSEPs can be used to monitor and identify early reversible cerebral damage to decrease the morbidity of the patients. To conclude, SSEPs monitoring must be considered in all the complex aneurysmal surgeries to limit the temporary clipping time and preventing postoperative neurological deficits.

\section{Conflict of Interest}

None declared.

\section{References}

1 Krayenbühl N, Erdem E, Oinas M, Krisht AF. Symptomatic and silent ischemia associated with microsurgical clipping of intracranial aneurysms: evaluation with diffusion-weighted MRI. Stroke 2009;40(1):129-133

2 Kashkoush AI, Jankowitz BT, Nguyen C, et al. Perioperative stroke after cerebral aneurysm clipping: risk factors and postoperative impact. J Clin Neurosci 2017;44:188-195

3 Kashkoush AI, Jankowitz BT, Gardner P, et al. Somatosensory evoked potentials during temporary arterial occlusion for intracranial aneurysm surgery: predictive value for perioperative stroke. World Neurosurg 2017;104:442-451

\section{Acute Sialadenitis and Threatened Airway following Posterior Fossa Surgery}

\author{
Ashutosh Kumar ${ }^{1} \quad$ Ajay P. Hrishi ${ }^{1}$ Neeraja Ajayan ${ }^{1}$ \\ ${ }^{1}$ Neuroanesthesia Division, Department of Anesthesiology, Sree \\ Chitra Tirunal Institute for Medical Sciences and Technology, \\ Trivandrum, Kerala, India
}

J Neuroanaesthesiol Crit Care 2021;8:224-226.

Anesthesia mumps (also known as acute sialadenitis) is a rare postoperative complication related to extreme rotation or flexion of the head during surgery. ${ }^{1}$ Acute sialadenitis causing acute airway obstruction and requiring emergent tracheostomy has not been reported in the past. We describe a case of acute submandibular and parotid sialadenitis causing acute respiratory distress after posterior fossa craniotomy for the right cerebellopontine $(\mathrm{CP})$ angle lesion. Informed consent has been obtained from the patient for the images in this article.

A 45-year-old female weighing $60 \mathrm{~kg}$ with no known comorbidities presented with vestibular schwannoma in the right $\mathrm{CP}$ cistern. The patient was posted for a right retrosigmoid suboccipital craniotomy and tumor excision in the left

\author{
Manikandan Sethuraman ${ }^{1}$
}

Address for correspondence Ajay P. Hrishi, MD, DM, MNAMS, MIMSA, Neuroanesthesia Division, Department of Anesthesiology, Sree Chitra Tirunal Institute for Medical Sciences and Technology, 4th Floor, C Block, Trivandrum 695011, Kerala, India (e-mail: drajay@sctimst.ac.in).

park bench position. In the operating room, the standard ASA (American Society of Anesthesiologists) monitors, such as electrocardiography (ECG), noninvasive blood pressure, and pulse oximetry $\left(\mathrm{SpO}_{2}\right)$, were initiated, and anesthesia was induced with propofol $2 \mathrm{mg} / \mathrm{kg}$, fentanyl $3 \mu \mathrm{g} / \mathrm{kg}$, and vecuronium $0.1 \mathrm{mg} / \mathrm{kg}$. The trachea was intubated with a $7.5-\mathrm{mm}$ cuffed PVC (polyvinyl chloride) endotracheal tube fixed on the left corner of the mouth to facilitate nerve monitoring of the right facial nerve, and a bite block was inserted. The patient was placed in the left park bench position, and the head was fixed in a Mayfield clamp. A two-finger width between the mandible and clavicle was confirmed. She was ventilated with oxygen and air, with $\mathrm{FiO}_{2}$ being 0.5 , and anesthesia was maintained with propofol-based total intravenous published online

September 17, 2020
DOI https://doi.org/

$10.1055 / \mathrm{s}-0040-1716424$

ISSN 2348-0548. (c) 2020. Indian Society of Neuroanaesthesiology and Critical Care.

This is an open access article published by Thieme under the terms of the Creative Commons Attribution-NonDerivative-NonCommercial-License, permitting copying and reproduction so long as the original work is given appropriate credit. Contents may not be used for commercial purposes, or adapted, remixed, transformed or built upon. (https://creativecommons.org/licenses/by-nc-nd/4.0/).

Thieme Medical and Scientific Publishers Pvt. Ltd. A-12, 2nd Floor, Sector 2, Noida-201301 UP, India 